\title{
A Framework for Maternal Physical Activities and Health Monitoring Using Wearable Sensors
}

\author{
Farman Ullah ${ }^{1, * \mathbb{D}}$, Asif Iqbal ${ }^{2}$, Sumbul Iqbal ${ }^{1}$, Daehan Kwak ${ }^{3} \mathbb{D}$, Hafeez Anwar ${ }^{1}$, Ajmal Khan ${ }^{1} \mathbb{D}$, \\ Rehmat Ullah ${ }^{4}$ (D), Huma Siddique ${ }^{1}$ and Kyung-Sup Kwak ${ }^{2, *(\mathbb{D}}$ \\ 1 Department of Electrical \& Computer Engineering, COMSATS University Islamabad-Attock Campus, \\ Punjab 43600, Pakistan; sp15-bee-037@ciit-attock.edu.pk (S.I.); hafeez.anwar@ciit-attock.edu.pk (H.A.); \\ drajmal@ciit-attock.edu.pk (A.K.); sp17-ree-016@ciit-attock.edu.pk (H.S.) \\ 2 Department of Information and Communication Engineering, Inha University, Incheon 22212, Korea; \\ asifsoul@inha.ac.kr \\ 3 Department of Computer Science, Kean University, Union, NJ 07083, USA; dkwak@kean.edu \\ 4 Department of Computer Systems Engineering, University of Engineering \& Technology, \\ Peshawar 25000, Pakistan; rehmatkttk@nwfpuet.edu.pk \\ * Correspondence: farmankttk@ciit-attock.edu.pk (F.U.); kskwak@inha.ac.kr (K.-S.K.)
}

check for updates

Citation: Ullah, F.; Iqbal, A.; Iqbal, S.; Kwak, D.; Anwar, H.; Khan, A.; Ullah,

R.; Siddique, H.; Kwak, K.-S. A

Framework for Maternal Physical Activities and Health Monitoring Using Wearable Sensors. Sensors 2021, 21, 4949. https://doi.org/10.3390/ s21154949

Academic Editor: Nizam Uddin Ahamed

Received: 23 May 2021

Accepted: 3 July 2021

Published: 21 July 2021

Publisher's Note: MDPI stays neutral with regard to jurisdictional claims in published maps and institutional affiliations.

Copyright: (c) 2021 by the authors. Licensee MDPI, Basel, Switzerland. This article is an open access article distributed under the terms and conditions of the Creative Commons Attribution (CC BY) license (https:/ / creativecommons.org/licenses/by/ $4.0 /)$.

\begin{abstract}
We propose a physical activity recognition and monitoring framework based on wearable sensors during maternity. A physical activity can either create or prevent health issues during a given stage of pregnancy depending on its intensity. Thus, it becomes very important to provide continuous feedback by recognizing a physical activity and its intensity. However, such continuous monitoring is very challenging during the whole period of maternity. In addition, maintaining a record of each physical activity, and the time for which it was performed, is also a non-trivial task. We aim at such problems by first recognizing a physical activity via the data of wearable sensors that are put on various parts of body. We avoid the use of smartphones for such task due to the inconvenience caused by wearing it for activities such as "eating". In our proposed framework, a module worn on body consists of three sensors: a 3-axis accelerometer, 3-axis gyroscope, and temperature sensor. The time-series data from these sensors are sent to a Raspberry-PI via Bluetooth Low Energy (BLE). Various statistical measures (features) of this data are then calculated and represented in features vectors. These feature vectors are then used to train a supervised machine learning algorithm called classifier for the recognition of physical activity from the sensors data. Based on such recognition, the proposed framework sends a message to the care-taker in case of unfavorable situation. We evaluated a number of well-known classifiers on various features developed from overlapped and non-overlapped window size of time-series data. Our novel dataset consists of 10 physical activities performed by 61 subjects at various stages of maternity. On the current dataset, we achieve the highest recognition rate of $89 \%$ which is encouraging for a monitoring and feedback system.
\end{abstract}

Keywords: maternal physical activity recognition; wearable sensors; human-centric computing; raspberry-PI; BLE

\section{Introduction}

Physical activities are often instrumental in the enhancement of human physical and mental health. Their absence, on the other hand, can cause adverse effects on well-being such as obesity [1]. Specifically, they are influential during particular medical conditions such as gravidity, more commonly known as pregnancy. It is a unique period in a woman's life where her lifestyle, behavior, and physical activeness can significantly affect her health, as well as that of her fetus [2]. It is shown that the physical activeness of a gravida improves both the maternal-fetal health [3-7] by avoiding adverse pregnancy complications and birth outcomes, such as pre-eclampsia, gestational diabetes, and preterm birth. Various standard health guidelines [8] exist around the world where moderate exercises are recommended 
during pregnancy with a special care about particular health conditions such as preeclampsia. However, during such conditions, certain physical activities are completely proscribed by the experts while others are limited $[9,10]$. A gravida (pregnant woman) should avoid physical activities such as prolong standing and all those carried out in high heat and humid environment. However, the lack of knowledge about the physical activities and the remoteness from a health specialist result in birth complications that prove life-threatening especially in developing countries [11].

This makes the close supervision and advice of experts important, which, if not taken into account, could result in serious health issues. Nonetheless, such supervision is often expensive and time-consuming due to the frequent and scheduled visits to the experts [12] To overcome these difficulties, a system based on the expert knowledge can be incorporated that frequently monitors the physical activities of a gravida and gives its recommendations. In this paper, we aim at the development of such a system by remotely recognizing and monitoring the physical activities of a gravida via the data acquired from the wearable sensors worn by her. Our proposed system recognizes the physical activity and then sends its feedback such as the type of activity and the time period for which it was performed. In this way, the monitoring of physical activities becomes convenient both locally (for the gravida) and remotely (for the health supervisor).

Figure 1 shows an overview of the proposed system that involves several steps such as data acquisition, processing, recognition, and feedback. The data from gravida are acquired via wearable sensors modules that contain an accelerometer, a gyroscope, and temperature sensors. These data are then sent to a server such as a Raspberry-Pi via Bluetooth to perform the main step of physical activity recognition. Feedback is sent back to the user side about the recognized activity.

However, recognition of the physical activity based on the information of wearable sensors [13-15] is a non-trivial task that involves many challenges. For instance, the recognition rate is affected by the sensor placement on the body where a given physical activity may become more recognizable with sensors worn on particular body positions than others. The activities which include posture, bending, and ambulation moments are better monitored by placing sensors at hip, pocket, ankle, and thigh position, while activities involving upper body requires sensors to be placed at arm, chest, neck or elbow for better recognition. Similarly, the sensors installed at the pocket position can better recognize biking, stairs up and down while using the wrist position gives better recognition for eating and smoking [16]. The second challenging factor in wearable sensor-based activity recognition is the selection of useful features for a given activity. The first- and second-order statistics of the data extracted from various sensors, such as the accelerometer and gyroscope and their combinations, affect the recognition rates of the physical activities. However, some features boost the recognition rates of certain physical activities while degrading those of others. Finally, the selection of a machine learning algorithm to achieve the highest possible recognition rate is also challenging. A supervised machine learning algorithm that learns the model first such as random forest classifier gives a higher recognition rate given the trade-off that it is a tedious offline training procedure that requires a massive amount of data. On the other hand, the online feature matching algorithms such as the KNN classifier require no offline training procedure and data, but they tend to become time-consuming while matching a given physical activity with exemplar activities stored in the database.

In order to cope with these challenges, the following details our novel contributions in this paper.

1. As gravidity is a special body condition both medically and physically $[17,18]$, we did not use the data of normal people to train the supervised machine learning algorithm for the activity recognition of gravidas. Instead, we collected a novel dataset of 10 physical activities from 61 gravidas who were at various stages of gravidity.

2. We performed features extraction on the acquired data using various statistical measures from both time and frequency domains. 
3. For the physical activity recognition on the novel dataset, we evaluated several classifiers and selected the one that gave the best cumulative result.

4. We provide Raspberry-PI- and GSM-based real-time activities and health monitoring of gravida to avoid unfavorable situations in case of emergency.

The rest of paper is organized as follows. Section 2 provides the literature review. Section 4 explains the features engineering and classifiers. The dataset description, results, and performance evaluation are discussed in Section 5. Finally, we conclude the paper in Section 6.

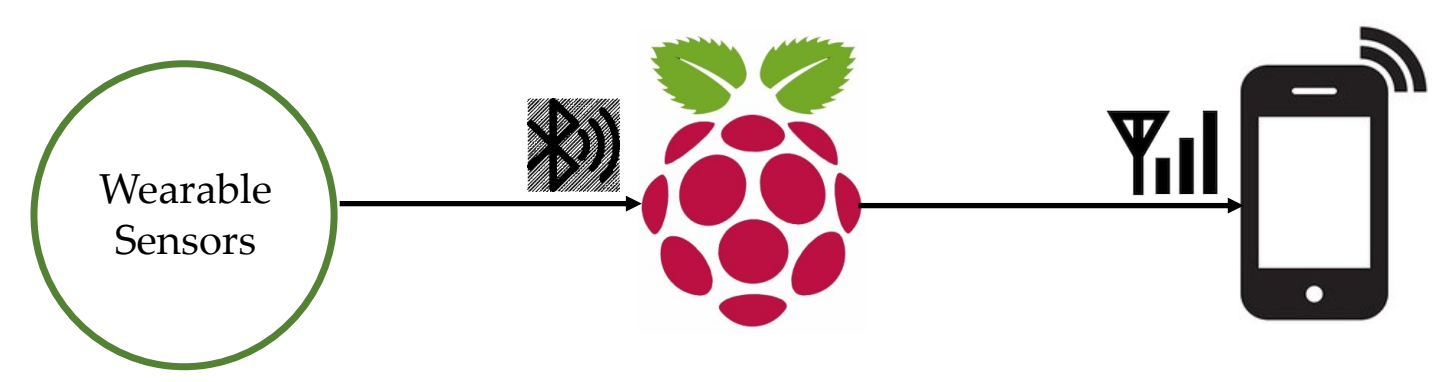

(a)

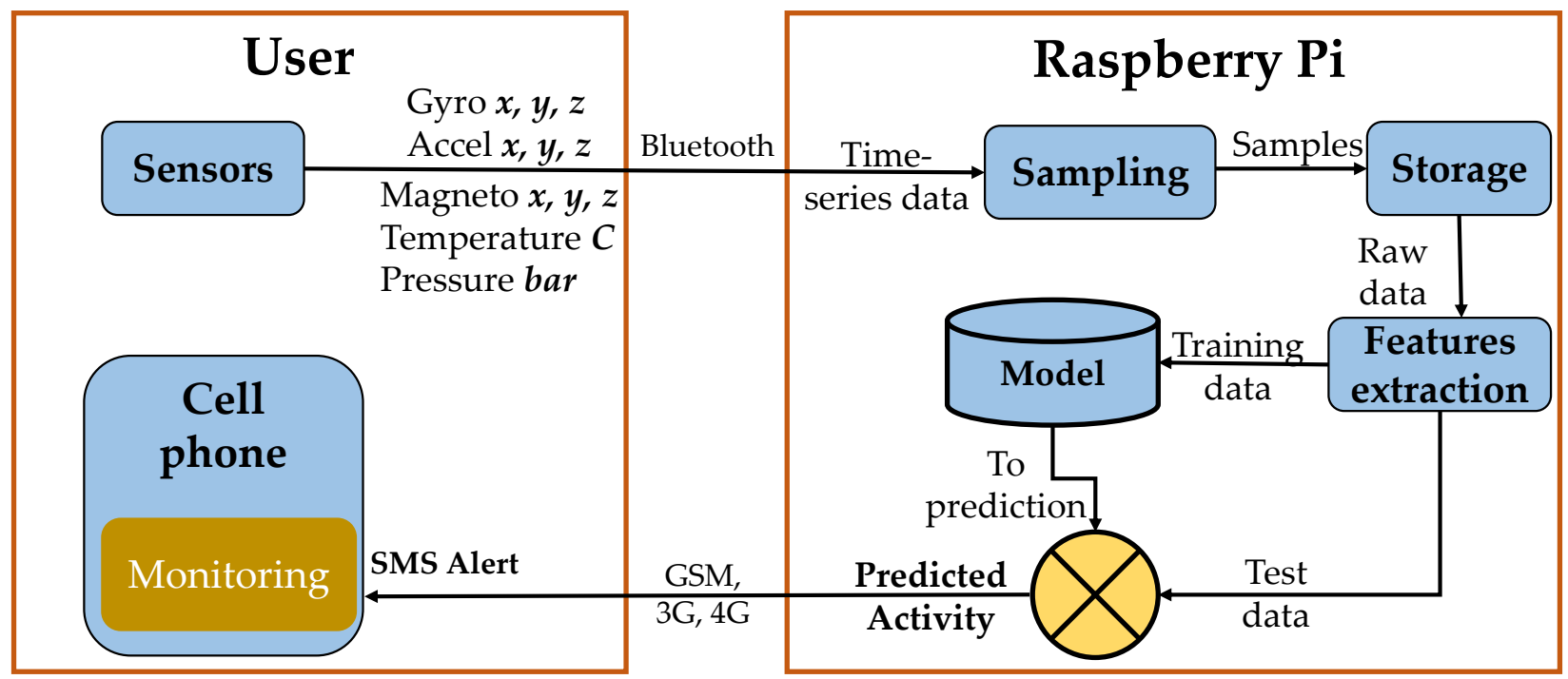

(b)

Figure 1. (a) Hardware and (b) software overview of the proposed framework.

\section{Literature Review}

In this section, we briefly introduce the prior contributions related to physical activities recognition (PAR) using wearable sensors. We summarize literature based on the following building blocks of a PAR system.

- Sensors used for the collection of data.

- Sensors placement on the body.

- Features vector construction from sensors data.

- Classification algorithms. 


\subsection{Sensors for PAR}

PAR is mainly dependent on the raw data acquired through sensors that can be ambient, mobile, or wearable such as smartwatches. Ambient sensors are installed in the environment and have no physical connection with the person whose data is being acquired [19]. These sensors include video cameras [20,21], microphones [22], motion sensors [23], and depth cameras such as Kinect sensor [24], etc. These sensing systems are static and area-bound (Wi-Fi or Bluetooth range) where they can only monitor activities in the bounded area. For instance, if the gravida is working in an office, then she needs two separate sensing systems. In addition to that, the activities performed outside these two infrastructures cannot be monitored. For continuous data acquiring and monitoring, mobile and wearable sensors are used.

The smartphones $[25,26]$ are equipped with multiple sensors such as an accelerometer, GPS trackers, Pulse sensor, gyroscope, etc. These sensors can acquire data remotely and accurately. However, the mobile sensor-based data acquisition system has some drawbacks [27]. Mostly, the smartphone is placed in a pocket position which reduces the accuracy of recognizing activities such as eating, typing, cooking, etc. Similarly, the continuous monitoring is also an issue with smartphones as they may stay away from the body in many cases, such as in handbags, for charging, lie on a table during office hours, etc. The body-worn sensors devices can avoid these issues and improve accuracy as they are continuous worn at various body positions. Consequently, a PAR system based on body worn sensors provides better results than those based on either ambient or mobile phone sensors [28,29].

\subsection{Sensors Placement on Various Body Parts}

The activity recognition accuracy highly depends on the sensors placement on various body parts. Performed physical activity can be better monitored by placing sensors on the body part that best suits the participant. The proper position of sensors solely depends on the activity being performed [30]. Furthermore, the literature shows that the PAR which include posture, bending, and ambulation moments are better monitored by placing sensors at hip, pocket, ankle, and thigh position, while activities involving upper body requires sensors to be placed at arm, chest, neck or elbow for proper recognition [31]. Table 1 shows the placement of body-worn devices on-body for various PAR.

Table 1. Body-worn devices placement on-body for PAR.

\begin{tabular}{ccc}
\hline S. No & Body-Worn Placement & Refs. \\
\hline 1. & Head & {$[32,33]$} \\
2. & Ear & {$[34]$} \\
3. & Shoulder & {$[35]$} \\
4. & Chest & {$[32,33,35,36]$} \\
5. & Arm (Elbow) & {$[32,36]$} \\
6. & Wrist & {$[32,37-39]$} \\
7. & Waist(Hip) & {$[32,38,40-42]$} \\
8. & Ankle & {$[34,37,38,40]$} \\
9. & Foot & {$[40]$} \\
10. & Knee & {$[34,43]$} \\
11. & Thigh & {$[32,33,38]$} \\
12. & Back & {$[35,43]$} \\
\hline
\end{tabular}

\subsection{Features Extraction from Sensors Data}

In PAR, the sensors data are collected using various sampling frequencies according to the nature of acquiring activity. Liu et al. [42], as a first step, preprocessed the signal using a low-pass filter to remove the DC-component and then extracted features from the processed signal. They extracted a feature vector of length 24 , including the mean, 
minimum, maximum, standard deviation, average peak frequency, root mean square, etc. The data are then segmented into a time-series segment known as windows size. Pannurat et al. [44] collected accelerometer data with $50 \mathrm{~Hz}$ and proposed a two-step process of feature extraction and selection. In the first step, they extracted 37 features using a window size of 1-s with 0.5-s overlap. In the second step, they used a Relief-F feature selection algorithm to select 7 features from the 37. Table 2 shows the literature summary of sensors, physical activities, the window size with overlapping and non-overlapping for features extraction, and corresponding extracted features. We adapted most of the features from the works in [45-48].

Table 2. Literature summary of sensors, physical activities, features extraction based on overlapping and non-overlapping, and selected features for HPAR.

\begin{tabular}{|c|c|c|c|c|}
\hline Refs. & Sensors & Activities & OL/NOL & Features Extracted \\
\hline [45] & $\begin{array}{l}\text { Accelerometer, } \\
\text { Gyroscope, } \\
\text { and Magnetometer }\end{array}$ & $\begin{array}{l}\text { PA1, PA7, PA10, PA11, } \\
\text { PA26 }\end{array}$ & NOL & $\begin{array}{c}\text { Mean, Variance, Kurtosis } \\
\text { Skewness Energy, Peak Signal } \\
\text { Value, Maximum Latency, } \\
\text { Peak-to-Peak Time, Peak-to-Peak } \\
\text { Slope, Latency, Amplitude Ratio, } \\
\text { Max. Amplitude, Min. } \\
\text { Amplitude }\end{array}$ \\
\hline [46] & $\begin{array}{l}\text { accelerometer, } \\
\text { gyroscope, } \\
\text { magnetometer, } \\
\text { quaternion }\end{array}$ & $\begin{array}{l}\text { 33-activities:PA7, PA26, } \\
\text { PA15, etc. }\end{array}$ & $(66 \%) \mathrm{OL}$ & $\begin{array}{l}\text { Mean, STD, median absolute } \\
\text { deviation, maximum and } \\
\text { minimum value, signal } \\
\text { magnitude area, coefficients of } \\
\text { auto-regression, index of } \\
\text { frequency with largest } \\
\text { coefficient, values of frequency } \\
\text { kurtosis and skewness etc. }\end{array}$ \\
\hline [49] & Accelerometer & $\begin{array}{l}\text { PA1, PA7, PA10, PA11, } \\
\text { PA12 }\end{array}$ & $(50 \%)$ OL, NOL & $\begin{array}{l}\text { Mean, Binned range, Standard } \\
\text { deviation, Time interval between } \\
\text { local peaks, Correlation, } \\
\text { Mean-dominant frequency, } \\
\text { Mean energy of frequency }\end{array}$ \\
\hline [50] & $\begin{array}{l}\text { Accelerometer, } \\
\text { Gyroscope }\end{array}$ & $\begin{array}{l}\text { PA29 (Hand and Body } \\
\text { Gestures) }\end{array}$ & $\begin{array}{r}(10,30,50 \\
60,80) \% \text { OL }\end{array}$ & $\begin{array}{c}\text { Convolutional Neural Network } \\
\text { based Features }\end{array}$ \\
\hline [51] & Accelerometer & $\begin{array}{l}\text { PA1, PA7, PA10, PA11, } \\
\text { PA24 }\end{array}$ & $(50 \%) \mathrm{OL}$ & $\begin{array}{l}\text { mean value, standard deviation, } \\
\text { median absolute deviation, } \\
\text { largest value, smallest value, } \\
\text { signal magnitude area, energy, } \\
\text { interquartile range, entropy, auto } \\
\text { regression coefficients }\end{array}$ \\
\hline [52] & $\begin{array}{l}\text { Accelerometer, } \\
\text { Gyroscope }\end{array}$ & $\begin{array}{l}\text { PA30, PA31, PA32, } \\
\text { PA33, PA34, PA35 }\end{array}$ & $(25 \%) \mathrm{OL}$ & $\begin{array}{c}\text { Entropy, Average, Standard } \\
\text { Deviation, Number of Peaks } \\
\text { Number of Valleys }\end{array}$ \\
\hline [53] & $\begin{array}{c}\text { Accelerometer, gyro, } \\
\text { Magneto, Heart rate, } \\
\text { ECG }\end{array}$ & $\begin{array}{l}\text { PA6, PA10, PA11, PA7, } \\
\text { PA8, PA9, PA21, PA36, } \\
\text { PA37, PA29 }\end{array}$ & (Variable size) OL & code-based features approach \\
\hline
\end{tabular}

Activities: PA1: Stairs up/down, PA2: Cooking, PA3: Eating, PA4: Exercise, PA5: Laundry, PA6: Lying, PA7: Walking, PA8: Front-bending, PA9: Side-bending, PA10: Standing, PA11: Sitting, PA12: Jogging, PA13: Playing (games), PA14: Reading, PA15: Cycling, PA16: Gardening, PA17: Rope skipping, PA18: Rowing, PA19: Driving car, PA20: Uphill/ downhill, PA21: Stand-to-Sit, Sit-to-Stand, PA22: Sit-to-Lie, Lie-to-Sit, PA23: Stand to-Lie, Lie-to-Stand, PA24: Biking, PA25: Knee-bending, PA26: Running, PA27: Jumping, PA28: Washing dishes, PA29: Other activities, PA30: Brushing Teeth, PA31: Comb Hair, PA32: Drinking, PA33: Scratch Chin, PA34: Take Meds, P3A5:Wash Hands, PA36: Front Elevation of Arms, PA37: Stretching of Hands, PA38: Office Work. 


\subsection{Classification Algorithms for PAR}

Classifiers are supervised learning algorithms where the parameters of their respective models are trained using the training data samples along with labels. The recognition performance of this trained model is then evaluated by using it to predict the labels of completely new test data. Various classifiers are evaluated by different PAR systems such as K-nearest neighbor (KNN), decision tree, random forest (RF), gradient boosting, multilayer perceptron (MLP), artificial neural network (ANN), support vector machine (SVM), etc. [54]. Table 3 summarizes some methods with respect to the physical activities, classifiers, and their achieved recognition rates.

Table 3. Literature summary of classifiers performance comparison for various physical activities.

\begin{tabular}{ccc}
\hline Refs. & Physical Activities & $\begin{array}{c}\text { Classifiers Performance Using Various } \\
\text { Metrics }\end{array}$ \\
\hline$[54]$ & P29-(8 different activities) & SVM: 99.5\%, Decision tree: 91.3\% \\
\hline$[55]$ & PA1, PA2, PA14, PA28, PA7, PA13, etc. & $\begin{array}{c}\text { Overall: 95\%, DT: 83\%, SVM: } 84 \%, \text { RF: 95\%, } \\
\text { ANN: } 96 \%\end{array}$ \\
\hline$[56]$ & PA1, PA27, PA6, PA12, P7, PA10 & ANN: 77\%, KNN: 75\%, RF: 89\%, SVM: 78\% \\
\hline [57] & PA1, PA6, PA7, PA10, PA11, PA15, & $\begin{array}{c}\text { About } 87 \pm 5 \% \text { for decision tree, SVM, } \\
\text { decision rules, KNN, Naive bayes, and RF }\end{array}$ \\
\hline$[58]$ & PA1, PA6, PA7, PA10, PA11 & RF: 80\%, MLP: $81 \%$ \\
\hline
\end{tabular}

\section{Data Set Description}

In this paper, we collect the data of pregnant women by installing the wearable sensor module at wrist position on either the left or right hand. We used the sensor placement at the wrist position because, mostly, the recognized activities involve hand movement. Sensor installation is easy at the wrist and can be managed as a smart watch by the maternal patient. We collect the data in a hospital under the supervision of a medical doctor (gynecologist). For data collection, we collected data from 61 subjects for ten physical activities that were mostly acquired from the literature of normal persons physical activities recognition. The activities are stairs up/down, cooking, eating, hands exercise, laundry, laying, walking, front bending, side bending, and standing. Figure 2 shows the distribution of maternal patients according to trimester, age, occupation, and anemia status. The participants performed each activity for 2-5 min according the physical condition of gravida and gynecologist suggestion. The sensors tag (wearable sensor module) was installed either on left or right wrist of the participant. The data were collected in hospital and at home so some of the activities were not performed by each participant. An average six activities were performed by each participant. 


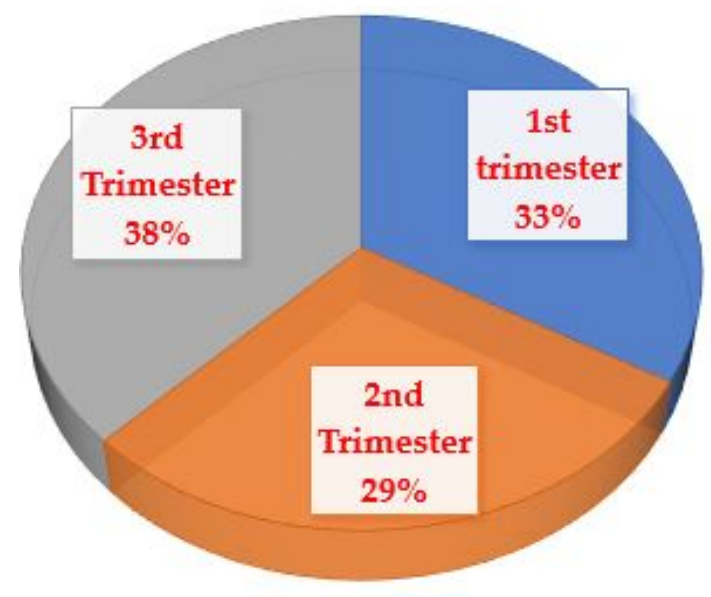

(a)

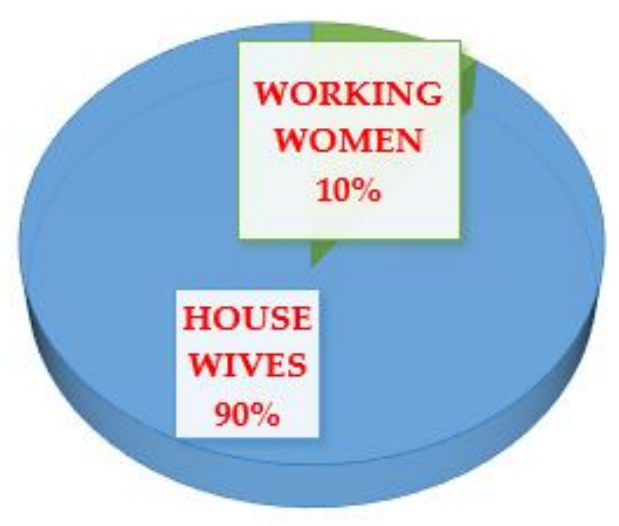

(c)

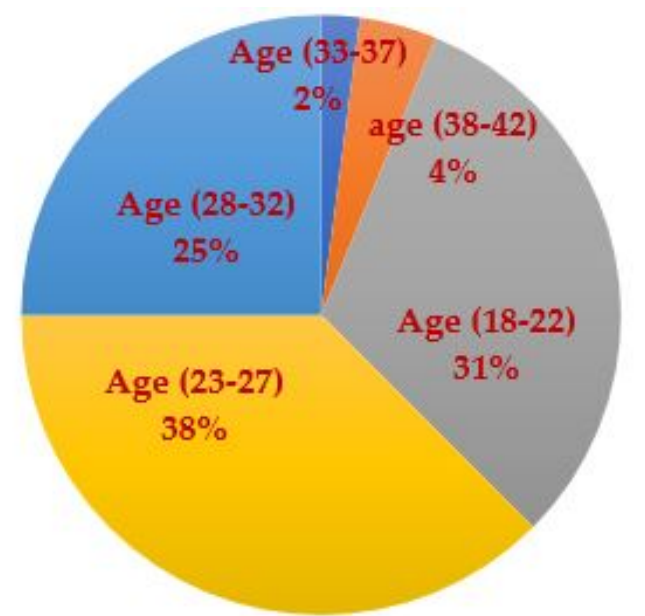

(b)

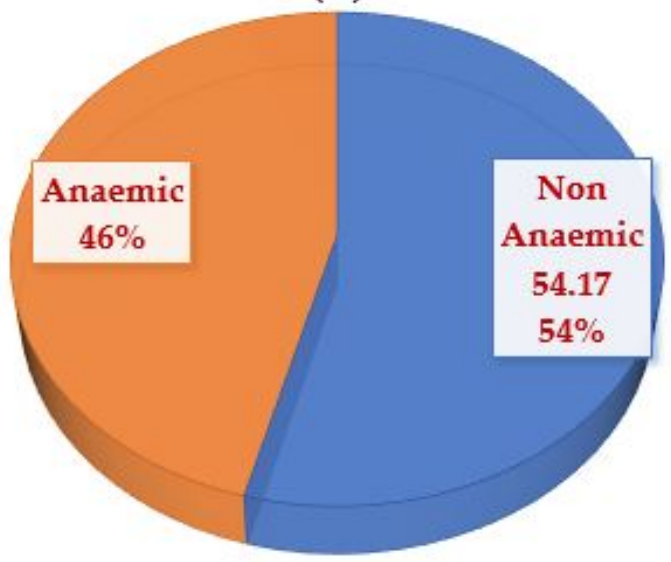

(d)

Figure 2. Maternal Patients Participants Distribution. (a) Trimester-based. (b) Age-based Distribution. (c) Profession-based. (d) Anemic and Non-anemic.

\section{The Proposed Maternal Physical Activities Recognition (MPAR) Framework}

The goal of our proposed MPAR system is to collect data from sensors worn by a gravida, recognize her physical activities via these data, and send the monitoring messages to a health supervisor. Figure 3 depicts the complete architecture of our proposed MPAR system which consists of the following main modules:

1. Sensors module and data acquisition

2. Sampling and features extraction

3. Activity recognition

4. Monitoring

In the following, we give further explanation of each module. 


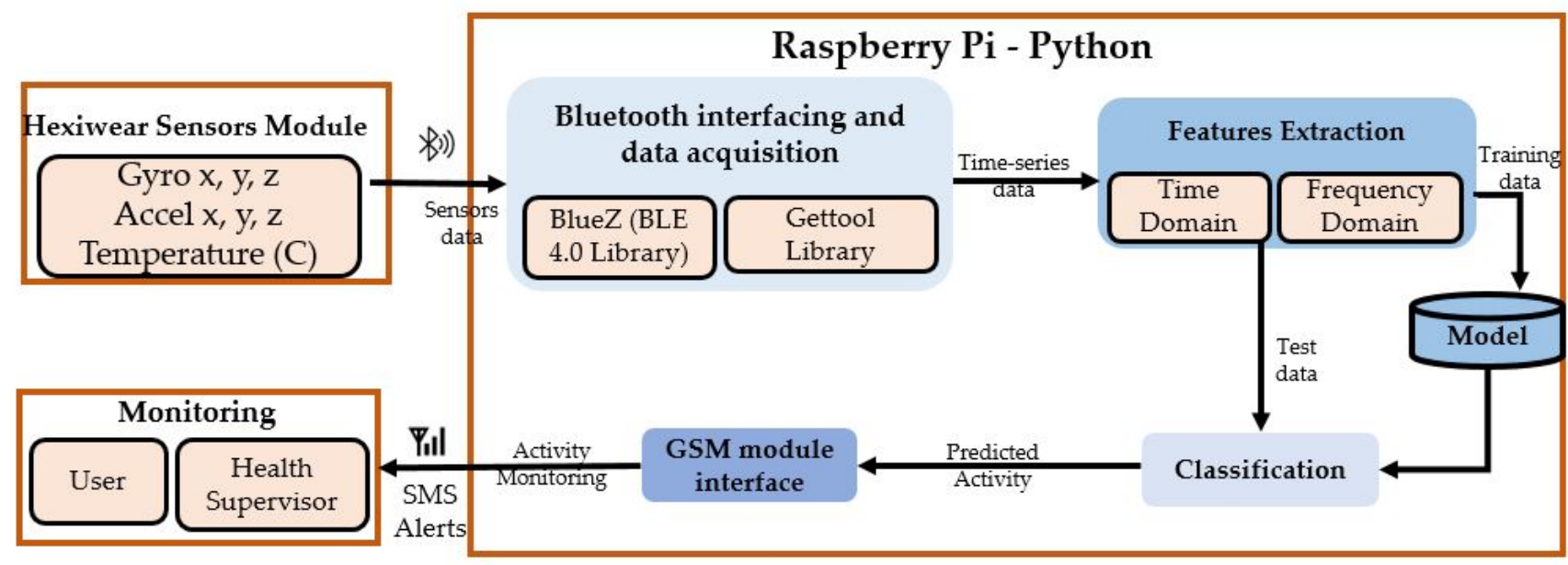

Figure 3. The proposed maternal physical activities recognition system architecture.

\subsection{Sensors Module and Data Acquisition}

We use a single wearable module of sensor that consists of an accelerometer, a gyroscope, and temperature sensors installed at the wrist position. Table 4 shows the configuration of sensors in terms of sampling and quantization. Both the accelerometer and gyroscope have three dimensions: $x$-axis, $y$-axis, and $z$-axis.

Table 4. Sensors configuration (sampling and quantization).

\begin{tabular}{ccc}
\hline Sensor & Sampling Frequency (Samples/Second) & Quantization Level \\
\hline Gyroscope $(x, y, z)$ & 50 & $16-\mathrm{bit}$ \\
Accelerometer $(x, y, z)$ & 50 & $16-\mathrm{bit}$ \\
Temperature & 1 & $16-\mathrm{bit}$ \\
\hline
\end{tabular}

The sensor module sends the data to a Raspberry PI using BLE 4.0 that has a communication range comparable to that of WiFi with an advantage of consuming almost $70 \%$ less energy during transmission. This leads to low battery power consumption of the sensor module [59]. On the software side, the connection between the Bluetooth BLE4 and Raspberry-PI is established using Python-based BlueZ while Gettool library is used for acquiring sensors data on Raspberry-PI [60].

\subsection{Sampling and Features Extraction}

We acquired the sensor data using various sampling frequencies and a sliding window approach where the two consecutive windows are either overlapping or non-overlapping. For instance, if the window size is one second, we get segments of the sensor data that are one second long. If the two consecutive windows become $50 \%$ overlapped, then their resultant segments will share $50 \%$ data. However, this is not the case in non-overlapping consecutive windows where the two segments do not share any data. We evaluate two values of window size which are one and two seconds. We use a 50\% overlap, which means a $0.5 \mathrm{~s}$ overlap in consecutive windows of $1 \mathrm{~s}$ and a $1 \mathrm{~s}$ overlap in consecutive windows of $2 \mathrm{~s}$. Each individual feature is extracted using 50 and 100 samples of accelerometer and gyroscope for $1 \mathrm{~s}$ and $2 \mathrm{~s}$ sliding windowing, respectively. We use 43 features to represent the sensors data that are shown graphically in listed in Figure 4 while their definitions are summarized in Table 5. 
Table 5. Feature extraction from sensor data.

\begin{tabular}{|c|c|c|}
\hline Features Name (Number) & Equations & Description \\
\hline Mean (4) & $\begin{array}{l}\qquad \mu=\frac{1}{N} \sum_{i=1}^{N} S x_{i} \\
\text { where } N \text { are total samples equal to the } \\
\text { window size and } S_{i} \text { is a sample point of } \\
\text { sensor data }\end{array}$ & $\begin{array}{l}\text { Mean/Average value calculation for 3D } \\
\text { Accelerometer }(x, y, z) \text { and temperature } \\
\text { used to different between slow moving } \\
\text { and fast moving activities. }\end{array}$ \\
\hline Standard Deviation (3) & $\sigma=\sqrt{\frac{1}{N} \sum_{i=1}^{N}\left(S x_{i}-\mu\right)^{2}}$ & $\begin{array}{l}\text { Find the spread in the accelerometer } \\
(x, y, z) \text { data around their mean. }\end{array}$ \\
\hline Cosine Similarity (3) & $\begin{array}{l}\qquad \operatorname{Cos} \theta=\frac{S x \cdot * S y}{\|S x\|\|S y\|} \\
\text { where } S x \text { and } S y \text { are the samples of } \\
\text { accelerometer of } x \text { and } y \text {, respectively. }\end{array}$ & $\begin{array}{l}\text { Find the cross-correlation in term of } \\
\text { cosine similarity to differentiate between } \\
\text { activities varying along with axis such as } \\
\text { walking and stairs up/down. It is } \\
\text { calculated between accelerometers } x \text { and } \\
\qquad y, x \text { and } z \text {, and } y \text { and } z \text {. }\end{array}$ \\
\hline Root Mean Square (RMS) (3) & $\begin{array}{l}\qquad R M S_{x}=\sqrt{\frac{1}{N} \sum_{i=1}^{N} G x_{i}} \\
\text { where } G x_{i} \text { is sample of } x \text {-axis gyroscope. }\end{array}$ & $\begin{array}{c}\text { Find the angular movement along } x \text {-axis, } \\
\text { y-axis, and } z \text {-axis, respectively. The } R M S \\
\text { is calculated for the gyroscope sensors } \\
\text { only. }\end{array}$ \\
\hline Skewness (3) & $S k_{x}=\frac{\sum_{i=1}^{N}\left(S x_{i}-\mu\right)^{3}}{\sigma_{x}^{3}}$ & $\begin{array}{c}\text { Skewness measures the degree of } \\
\text { symmetry in the accelerometer data } \\
\text { distribution. }\end{array}$ \\
\hline Kurtosis (3) & $K t_{x}=\frac{\sum_{i=1}^{N}\left(S x_{i}-\mu\right)^{4}}{N \sigma^{4}}$ & $\begin{array}{c}\text { Kurtosis measures the degree of } \\
\text { tailedness in the accelerometer data } \\
\text { distribution. }\end{array}$ \\
\hline Max value (3) & $A c c x_{\max }=\max \left\{S x_{i}\right\}$ & $\begin{array}{l}\text { Calculate the maximum value of } \\
\text { accelerometer }(x, y, z)\end{array}$ \\
\hline Min value (3) & $A c c x_{\min }=\min \left\{S x_{i}\right\}$ & $\begin{array}{l}\text { Calculate the minimum value of } \\
\text { accelerometer }(x, y, z)\end{array}$ \\
\hline Zero crossing (3) & $\begin{array}{l}Z C=\operatorname{count}\left\{\left(\left(S x_{i}<0\right) \& \&\left(S x_{i+1}>\right.\right.\right. \\
\left.\left.0)) \|\left(S x_{i}>0\right) \& \&\left(S x_{i+1}<0\right)\right)\right\}\end{array}$ & $\begin{array}{l}\text { Zero-Crossing is the number of times the } \\
\text { signals crosses zero and its sign is } \\
\text { changed.we consider ZC for the } \\
\text { accelerometer along three axes. }\end{array}$ \\
\hline Frequency Domain Features (6) & $H(k)=\sum_{n=0}^{N-1} x(n) e^{-2 j \pi\left(\frac{k n}{N}\right)}$ & $\begin{array}{l}\text { In this paper, we consider six frequency } \\
\text { domain features based on the Fast } \\
\text { Fourier Transform (FFT) of acceleration } \\
\text { data. The six features are the FFT } \\
\text { magnitude: } \text { peak }_{f}, \text { low }_{f 1}, \text { low }_{f 2}, \text { low }_{f 3} \text {, } \\
\text { med }_{f} \text {, and } \text { high }_{f} .\end{array}$ \\
\hline Entropy (3) & Entropy $=\frac{-1}{N} \sum_{i=0}^{N-1} p x_{i} \log p x_{i}$ & $\begin{array}{l}\text { Used for differentiation between } \\
\text { activities of static and dynamic nature. }\end{array}$ \\
\hline Quartile Range (3) & $Q_{1}=l+\frac{h}{f}\left(\frac{N}{4}-C\right)$ & $\begin{array}{l}\text { We find the first quartile (Q1), and it is } \\
\text { defined as the middle number between } \\
\text { the smallest number and the median of } \\
\text { the sample data. }\end{array}$ \\
\hline $\begin{array}{c}\text { Absolute Time Difference between } \\
\text { Peaks (3) }\end{array}$ & $\left|t_{\text {maxpeak }}-t_{\text {minpeak }}\right|$ & $\begin{array}{l}\text { It is calculated by taking absolute } \\
\text { difference of time instance of maximum } \\
\text { and minimum peak. }\end{array}$ \\
\hline
\end{tabular}




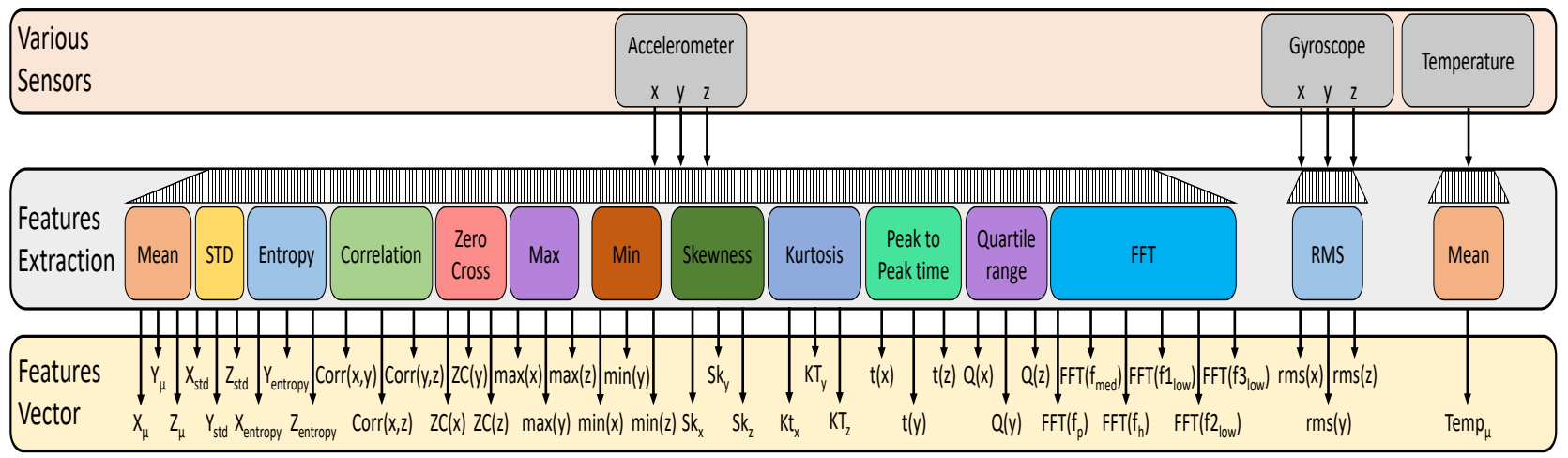

Figure 4. Feature vector construction.

\subsection{Activity Recognition via Supervised Machine Learning (Classification)}

We evaluated a number of classifiers using WEKA [61] for our proposed MPAR system. Each classifier follows the general rule of supervised machine learning algorithms, where the classifier parameters are trained with the help of a training set and then its classification/recognition performance is evaluated with a completely disjoint test set. Our dataset consists of 10 physical activities represented via their feature vectors as shown previously. This dataset needs to be split into two disjoint training and test sets. However, for achieving the best recognition rate, the dataset is randomly split in training and test sets with various percentages of 90-10, 80-20, and 70-30. Consequently, experiments for each split are repeated multiple times and an average physical activity recognition rate is calculated. Table 6 shows the WEKA parameters configuration of the evaluated classifiers.

Table 6. Classification algorithms used to evaluate the performance comparison.

\begin{tabular}{ccc}
\hline Classifier Type & WEKA Configuration & Abbreviation \\
\hline K-Nearest Neighbors [62] & $\mathrm{K}=1$, Distance $=$ Manhattan & KNN \\
Decision Tree [48] & Tree max depth $=50$ & J48 \\
Random Forest [63] & No. of tress $=100$ & RF \\
Induction rules [64] & ratio of data for growing and pruning $=0.95$ & IR \\
Gradient boosted trees [65] & No. of tress = 100, depth $=50$ & GBT \\
\hline
\end{tabular}

\subsection{Monitoring}

Mostly, people do not access to the data networks at all times. However, the GSM coverage is available at every place in a country. In order to provide the remote monitoring of a pregnant woman in case of an emergency or unfavorable conditions occur, we interfaced a GSM SIM900 module through a serial port with Raspberry-PI. The module keeps the numbers of registered gynecologists and care takers. The Raspberry-PI-based system monitors the maternal physical activities of the maternal woman, and if she is performing an activity that is not recommended it will send a message to the registered numbers..

\section{Results and Discussion}

Table 7 shows the feature extracted records of activities data acquired from gravidas. We used two different window sizes, i.e., one second and two seconds, and two configurations, i.e., overlapping and non-overlapping. In one second window size, the $0.5 \mathrm{~s}$ time-series data are overlapped and in two seconds window size the one second time-series data are overlapped. In this section, we show the recognition rates achieved by varying the following parameters. 
Table 7. Features Extracted Dataset Description using Different Window Size and Overlapping/Non-Overlapping.

\begin{tabular}{|c|c|c|c|c|}
\hline $\begin{array}{l}\text { Activity Name } \\
\text { (Label) }\end{array}$ & $\begin{array}{l}\text { Window Size }=1 \& \\
\text { Non-Overlapping }\end{array}$ & $\begin{array}{l}\text { Window Size }=1 \& \\
\text { Overlapping }\end{array}$ & $\begin{array}{l}\text { Window Size }=2 \& \\
\text { Non-Overlapping }\end{array}$ & $\begin{array}{l}\text { Window Size }=2 \& \\
\text { Overlapping }\end{array}$ \\
\hline $\begin{array}{l}\text { Stairs Up/Down } \\
\text { (MPA1) }\end{array}$ & 2217 & 3321 & 1052 & 1663 \\
\hline Cooking (MPA2) & 1850 & 3082 & 1018 & 1542 \\
\hline Eating (MPA3) & 1945 & 2929 & 968 & 1465 \\
\hline $\begin{array}{l}\text { Hands Exercise } \\
\text { (MPA4) }\end{array}$ & 2997 & 5187 & 1574 & 2521 \\
\hline Laundry (MPA5) & 1703 & 2566 & 849 & 1284 \\
\hline Laying (MPA6) & 2025 & 3050 & 1009 & 1526 \\
\hline Walking (MPA7) & 3411 & 5077 & 1720 & 2501 \\
\hline $\begin{array}{l}\text { Front Bending } \\
\text { (MPA8) }\end{array}$ & 612 & 922 & 305 & 462 \\
\hline Side Bending (MPA9) & 1908 & 3107 & 1087 & 1556 \\
\hline Standing (MPA10) & 857 & 1472 & 427 & 736 \\
\hline
\end{tabular}

- Sampling window size (overlapped and non-overlapped)

- Train and test split

- Type of classifier

Figure 5 shows the results for all the above mentioned parameters. We summarize the main points of the achieved results in the following.

1. The sampling overlapped window of one second performs best in most of the cases except for KNN classifier.

2. The overall recognition rate of $80-20 \%$ data split is better than the other two.

3. The gradient boosted tree (GBT) classifier outperforms all the classifiers while KNN performs the worst of all.

4. The highest accuracy of $89 \%$ is achieved by GBT where the train-test split is $90-10 \%$ and sampling overlapped window size is one second.

5. The accuracy achieved by RF classifier is comparable to that of GBT in most of the cases. However, GBT has a higher computational complexity than RF, due to which we selected RF for the Raspberry Pi implementation.

6. The overall performance comparison depicts that the tree-based classifiers achieve higher accuracy than other classification algorithms.

Based on these observations, in the rest of this section, we shall explain the results achieved via RF classifier and with an overlapping sampling window of one second. 


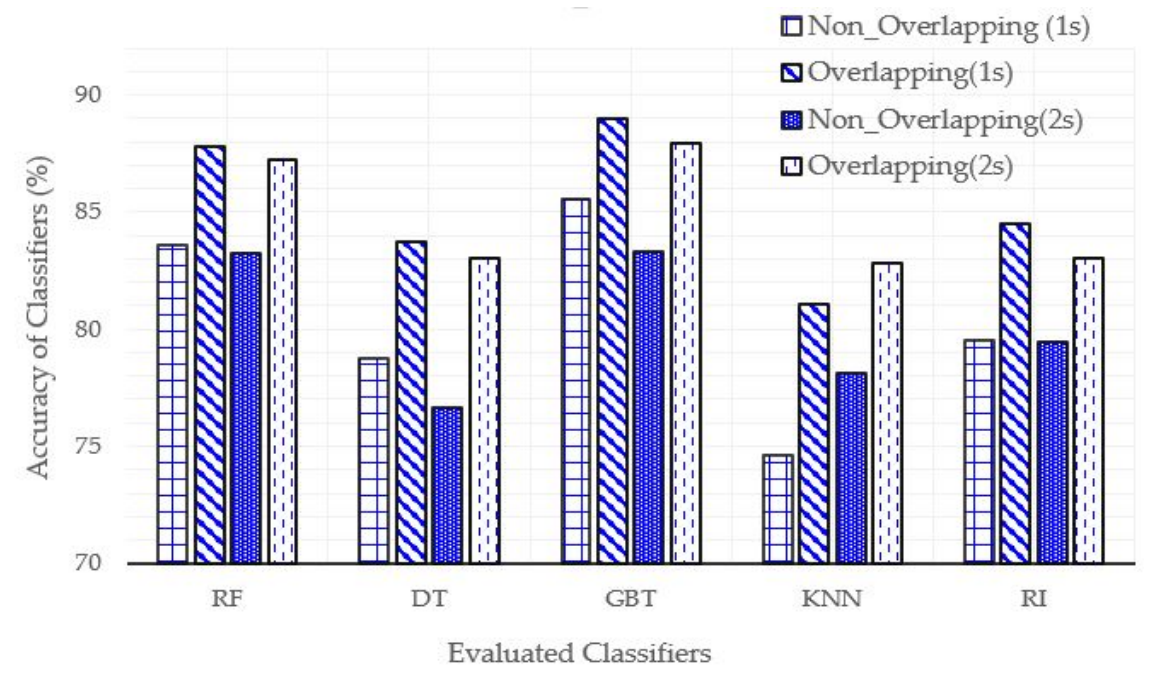

(a)

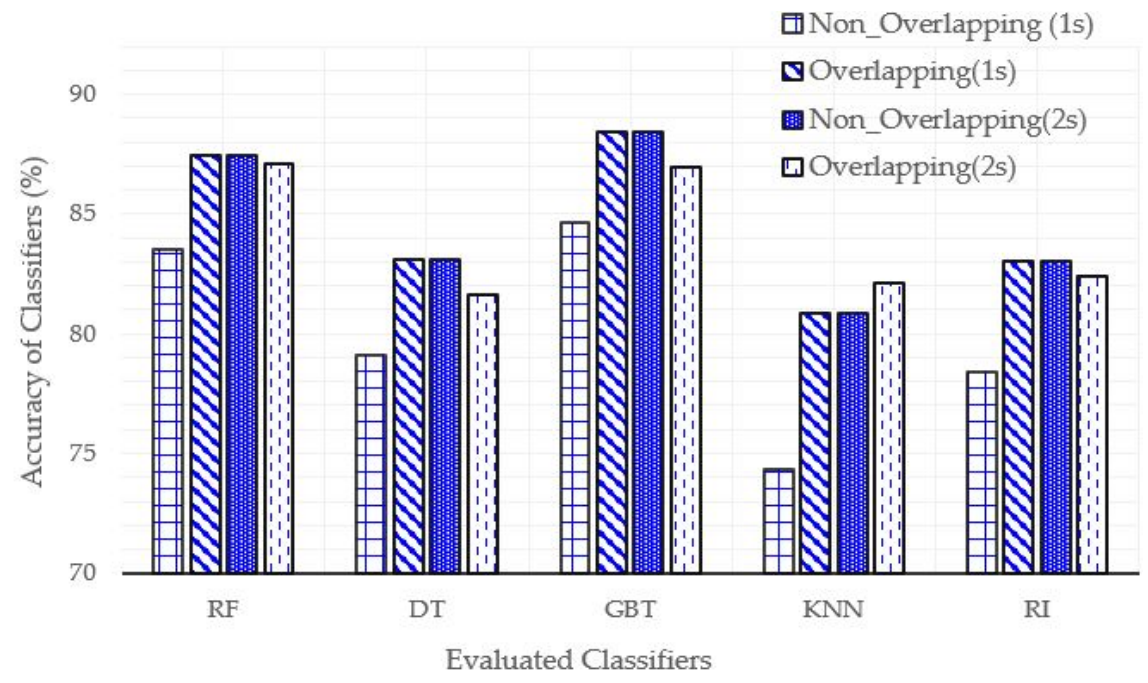

(b)

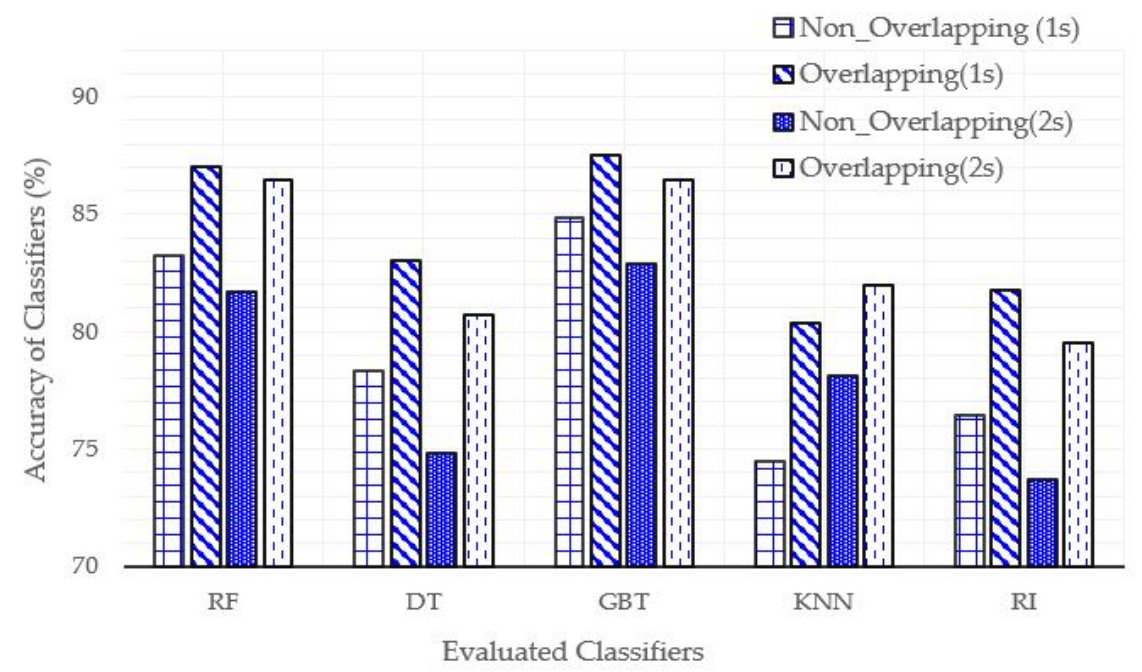

(c)

Figure 5. Classifiers performance comparison using various percentages of train-test splits: (a) 90-10, (b) 80-20, and (c) 70-30. 
Figure 6 shows the confusion matrices of individual activity recognition using all the three settings of dataset split. The following are the main observations.

1. The most recognized activity is front bending (MPA8), which is one of the most affecting physical activity during pregnancy. The best recognition rate achieved for this activity is almost $98 \%$ with the dataset split of 90-10.

2. The least recognized activity is standing (MPA10) which is also the least important among the current list of activities.

3. Side bending (MPA9) has greater confusion with the hand exercise (MPA4). Similarly, the standing activity (MPA10) has greater confusion with the hand exercise (MPA4). This is because the sensor module is installed at one hand wrist position and in all three activities there is little variation of linear and angular moments to perform these three activities.

4. Stairs walk (up/down) (MPA1) is confused with walking (MPA7), which is very convincing because during pregnancy climbing up or down the stairs is done with extreme care. This makes the stair walk very similar to the normal walk and consequently, the classifier confuses them for most of the times.

5. The physical activities where recognition rate is either equal to or higher than $90 \%$ are stairs Up/down (MPA1), cooking (MPA2), laying (MPA6), walking (MPA7), and front bending (MPA8).

6. All other activities except for side bending (MPA9) and standing (MPA10) are recognized with a rate of more than $85 \%$.

\begin{tabular}{|c|c|c|c|c|c|c|c|c|c|c|}
\hline MPA1 & 299 & $\mathbf{0}$ & 1 & $\mathbf{0}$ & 1 & 7 & 12 & $\mathbf{0}$ & 1 & 3 \\
\hline MPA2 & 2 & 278 & 6 & 1 & 5 & 2 & 3 & $\mathbf{0}$ & 0 & 4 \\
\hline MPA3 & 1 & 1 & 253 & 1 & 6 & 1 & 2 & $\mathbf{0}$ & 3 & 1 \\
\hline MPA4 & 2 & 11 & 3 & 451 & 10 & 3 & 8 & $\mathbf{0}$ & 56 & 21 \\
\hline MPA5 & 1 & 9 & 7 & 1 & 227 & 2 & 6 & $\mathbf{0}$ & 1 & 33 \\
\hline MPA6 & $\mathbf{0}$ & 1 & 3 & $\mathbf{0}$ & 3 & 279 & 1 & $\mathbf{0}$ & 1 & $\mathbf{0}$ \\
\hline MPA7 & 26 & 6 & 12 & 8 & 5 & 10 & 467 & 1 & 11 & 5 \\
\hline MPA8 & $\mathbf{0}$ & $\mathbf{0}$ & $\mathbf{0}$ & $\mathbf{0}$ & $\mathbf{0}$ & $\mathbf{0}$ & $\mathbf{0}$ & 90 & 2 & $\mathbf{0}$ \\
\hline MPA9 & 0 & 0 & 6 & 34 & $\mathbf{0}$ & 1 & 2 & 1 & 236 & $\mathbf{0}$ \\
\hline MPA10 & 1 & 2 & 2 & 23 & $\mathbf{0}$ & 0 & $\mathbf{0}$ & $\mathbf{0}$ & $\mathbf{0}$ & 110 \\
\hline & MPA1 & MPA2 & MPA3 & MPA4 & MPA5 & MPA6 & MPA7 & MPA8 & MPA9 & MPA10 \\
\hline
\end{tabular}

\section{Actual Physical Activities}

(a) Confusion matrix for $90-10 \%$ data split

\begin{tabular}{|c|c|c|c|c|c|c|c|c|c|c|}
\hline MPA1 & 606 & 3 & 6 & 2 & 2 & 10 & 24 & $\mathbf{0}$ & 1 & 6 \\
\hline MPA2 & 1 & 558 & 13 & 5 & 11 & 5 & 13 & $\mathbf{0}$ & $\mathbf{0}$ & 8 \\
\hline MPA3 & 2 & 5 & 504 & 6 & 11 & 7 & 3 & 0 & 2 & 2 \\
\hline MPA4 & 1 & 19 & 10 & 895 & 23 & 6 & 23 & 0 & 113 & 46 \\
\hline MPA5 & 6 & 17 & 20 & 2 & 453 & 8 & 7 & $\mathbf{0}$ & 0 & 5 \\
\hline MPA6 & 2 & 3 & 3 & $\mathbf{0}$ & 4 & 553 & 3 & 0 & 2 & $\mathbf{0}$ \\
\hline MPA7 & 44 & 7 & 18 & 14 & 9 & 20 & 921 & 2 & 25 & 12 \\
\hline MPA8 & 1 & 1 & 0 & 0 & $\mathbf{0}$ & 0 & $\mathbf{0}$ & 179 & 4 & 0 \\
\hline MPA9 & $\mathbf{0}$ & $\mathbf{0}$ & 10 & 76 & $\mathbf{0}$ & 1 & 5 & 3 & 474 & 1 \\
\hline MPA10 & 1 & 3 & 2 & 37 & $\mathbf{0}$ & $\mathbf{0}$ & 2 & $\mathbf{0}$ & 0 & 214 \\
\hline & MPA1 & MPA2 & MPA3 & MPA4 & MPA5 & MPA6 & MPA7 & MPA8 & MPA9 & MPA10 \\
\hline
\end{tabular}

\section{Actual Physical Activities}

(b) Confusion matrix for $80-20 \%$ data split

Figure 6. Cont. 


\begin{tabular}{|c|c|c|c|c|c|c|c|c|c|c|}
\hline MPA1 & 895 & 4 & 15 & 1 & 7 & 18 & 28 & $\mathbf{0}$ & 4 & 11 \\
\hline MPA2 & 2 & 826 & 15 & 14 & 17 & 9 & 20 & $\mathbf{0}$ & 1 & 17 \\
\hline MPA3 & 6 & 13 & 723 & 11 & 15 & 7 & 6 & $\mathbf{0}$ & 5 & 4 \\
\hline MPA4 & 5 & 32 & 23 & 1345 & 28 & 7 & 40 & $\mathbf{0}$ & 165 & 53 \\
\hline MPA5 & 6 & 29 & 29 & 3 & 687 & 10 & 19 & $\mathbf{0}$ & 2 & 6 \\
\hline MPA6 & 2 & 5 & 8 & 1 & 2 & 836 & 5 & 4 & 1 & $\mathbf{0}$ \\
\hline MPA7 & 76 & 11 & 35 & 16 & 11 & 26 & 1377 & 2 & 28 & 22 \\
\hline MPA8 & $\mathbf{0}$ & $\mathbf{0}$ & 1 & $\mathbf{0}$ & $\mathbf{0}$ & $\mathbf{0}$ & $\mathbf{0}$ & 267 & 6 & $\mathbf{0}$ \\
\hline MPA9 & $\mathbf{0}$ & $\mathbf{0}$ & 24 & 113 & 1 & 1 & 5 & 4 & 720 & 2 \\
\hline MPA10 & 4 & 5 & 6 & 52 & 2 & 1 & 2 & $\mathbf{0}$ & $\mathbf{0}$ & 327 \\
\hline & MPA1 & MPA2 & MPA3 & MPA4 & MPA5 & MPA6 & MPA7 & MPA8 & MPA9 & MPA10 \\
\hline
\end{tabular}

(c) Confusion matrix for $70-30 \%$ data split

Figure 6. Confusion matrices achieved with a RF classifier where the training and test sets are split in various ratios.

\section{Conclusions and Future Works}

In this paper, we proposed a platform for maternal physical activities recognition using wearable sensors. The proposed architecture consists of a wearable sensors module that acquires the activity time-series sensory data and sends them to a Raspberry-PI based processing platform to extract the features and recognize the activity. We evaluated the window sizes with overlapping and non-overlapping to evaluate the performance of acquired maternal data and proposed platform. The experimental results showed that the window size of one second with overlapping technique perform better on all classification algorithms. The maternal physical activities data of ten activities are collected of 61 pregnant women. Five classification algorithms are evaluated to find the better algorithm that can be implemented on a real-time platform for maternal activities recognition. Overall, the proposed system recognize the activity with higher accuracy of $89 \%$, which is encouraging, effective, and reliable.

In future work, we are planning to investigate the main aspects. The first aspect is considering the deep convolutional neural network for automatic features extraction and recognition. On the other hand, we want to expand the dataset by incorporating more activities and a larger number of participants. Furthermore, we are working on fusing sensors including breathing and ECG sensors, and sensors installed at multiple locations of body simultaneously.

Author Contributions: Conceptualization, F.U.; Data curation, S.I., A.K. and H.S.; Formal analysis, A.I. and H.A.; Funding acquisition, K.-S.K.; Investigation, F.U., D.K. and R.U.; Methodology, A.I., S.I., H.A. and H.S.; Software, S.I., A.K. and R.U.; Supervision, F.U. and K.-S.K.; Validation, A.K. and K.-S.K.; Writing —original draft, F.U. and H.A.; Writing—review and editing, D.K. and K.-S.K. All authors have read and agreed to the published version of the manuscript.

Funding: This research was funded by a National Research Foundation of Korea Grant funded by the Korean Government (Ministry of Science and ICT)—NRF-2020R1A2B5B02002478.

Institutional Review Board Statement: The study was conducted according to the guidelines of the Declaration of ECE Department CUI Attock Campus, and approved by the Graduate and Research Ethic Committee.

Informed Consent Statement: Informed consent was obtained from all subjects involved in the study through verbal and in written format.

Data Availability Statement: The dataset is available with the first author and will be provided on request.

Conflicts of Interest: The authors declare no conflict of interest. 


\section{References}

1. Bosems, S. A ubiquitous system for smart reasoning for well-being at home and at work. In Proceedings of the 2012 IEEE International Conference on Pervasive Computing and Communications Workshops (PERCOM Workshops), Lugano, Switzerland, 19-23 March 2012; pp. 534-535.

2. Davenport, M.H.; McCurdy, A.P.; Mottola, M.F.; Skow, R.J.; Meah, V.L.; Poitras, V.J.; Garcia, A.J.; Gray, C.E.; Barrowman, N.; Riske, L.; et al. Impact of prenatal exercise on both prenatal and postnatal anxiety and depressive symptoms: A systematic review and meta-analysis. Br. J. Sports Med. 2018, 52, 1376-1385. [CrossRef] [PubMed]

3. Reyes, L.M.; Davenport, M.H. Exercise as a therapeutic intervention to optimize fetal weight. Pharmacol. Res. 2018, 132, 160-167. [CrossRef] [PubMed]

4. Perales, M.; Santos-Lozano, A.; Ruiz, J.R.; Lucia, A.; Barakat, R. Benefits of aerobic or resistance training during pregnancy on maternal health and perinatal outcomes: A systematic review. Early Hum. Dev. 2016, 94, 43-48. [CrossRef] [PubMed]

5. Tobias, D.K.; Zhang, C.; Dam, R.M.V.; Bowers, K.; Hu, F.B. Physical activity before and during pregnancy and risk of gestational diabetes mellitus: A meta-analysis. Diabetes Care 2011, 34, 223-229. [CrossRef]

6. Cedergren, M.I. Maternal morbid obesity and the risk of adverse pregnancy outcome. Obstet. Gynecol. 2004, 103, 219-224. [CrossRef]

7. Sorensen, T.K.; Williams, M.A.; Lee, I.; Dashow, E.E.; Thompson, M.L.; Luthy, D.A. Recreational physical activity during pregnancy and risk of preeclampsia. Hypertension 2003, 41, 1273-1280. [CrossRef]

8. Poudevigne, M.S.; O'Connor, P.J. A review of physical activity patterns in pregnant women and their relationship to psychological health. Sports Med. 2006, 36, 19-38. [CrossRef]

9. Mottola, M.F.; Davenport, M.H.; Ruchat, S.; Davies, G.A.; Poitras, V.J.; Gray, C.E.; Garcia, A.J.; Barrowman, N.; Adamo, K.B.; Duggan, M.; et al. 2019 Canadian guideline for physical activity throughout pregnancy. Br. J. Sports Med. 2018, 52, 1339-1346. [CrossRef]

10. Hinman, S.K.; Smith, K.B.; Quillen, D.M.; Smith, M.S. Exercise in pregnancy: A clinical review. Sports Health 2015, 7, 527-531. [CrossRef]

11. Agha, S. A profile of women at the highest risk of maternal death in Pakistan. Health Policy Plan. 2014, 30, 830-836. [CrossRef]

12. Bougia, P.; Karvounis, E.; Ifotiadis, D. Smart medical textiles for monitoring pregnancy. In Smart Textiles for Medicine and Healthcare: Materials, Systems and Applications; CRC Press: Boca Raton, FL, USA, 2007; pp. 183-205.

13. Clifton, L.A.; Clifton, D.A.; Pimentel, M.A.F.; Watkinson, P.J.; Tarassenko, L. Predictive monitoring of mobile patients by combining clinical observations with data from wearable sensors. IEEE J. Biomed. Health Inform. 2014, 18, 722-730. [CrossRef] [PubMed]

14. Free, C.; Philipps, G. The effectiveness of mobile-health technology-based health behaviour change or disease management interventions for health care consumers: A systematic review. PLoS Med. 2013, 10, e1001362. [CrossRef]

15. World Health Organization (WHO) Report. Available online: https://www.who.int/news-room/fact-sheets/detail/maternalmortality (accessed on 23 July 2020 ).

16. Shoaib, M.; Bosch, S.; Incel, O.D.; Scholten, H.; Havinga, P.J.M. Complex human activity recognition using smartphone and wrist-worn motion sensors. Sensors 2016, 16, 426. [CrossRef]

17. Lopez, B.D.B.; Aguirre, J.A.A.; Coronado, D.A.R.; Gonzalez, P.A. Wearable technology model to control and monitor hypertension during pregnancy. In Proceedings of the 2018 13th Iberian Conference on Information Systems and Technologies (CISTI), Caceres, Spain, 13-16 June 2018; pp. 1-6.

18. Penders, J.; Altini, M.; Hoof, C.V.; Dy, E. Wearable sensors for healthier pregnancies. Proc. IEEE 2015, 103, 179-191. [CrossRef]

19. Cook, D.J.; Augusto, J.C.; Jakkula, V.R. Ambient intelligence: Technologies, applications, and opportunities. Pervasive Mob. Comput. 2009, 5, 277-298. [CrossRef]

20. Amirjavid, F.; Spachos, P.; Plataniotis, K.N. 3-D object localization in smart homes: A distributed sensor and video mining approach. IEEE Syst. J. 2018, 12, 1307-1316. [CrossRef]

21. Iqbal, A.; Ullah, F.; Anwar, H.; Kwak, K.S.; Imran, M.; Jamal, W.; ur Rahman, A. Interoperable Internet-of-Things platform for smart home system using Web-of-Objects and cloud. Sustain. Cities Soc. 2018, 38, 636-646. [CrossRef]

22. Liang, Y.; Zhou, X.; Guo, B.; Yu, Z. Activity Recognition Using Ubiquitous Sensors: An Overview. In Wearable Technologies: Concepts, Methodologies, Tools, and Applications; IGI Global: Hershey, PA, USA, 2018; pp. 199-230.

23. Zhu, S.; Xu, J.; Guo, H.; Liu, Q.; Wu, S.; Wang, H. Indoor Human Activity Recognition Based on Ambient Radar with Signal Processing and Machine Learning. In Proceedings of the 2018 IEEE International Conference on Communications (ICC), Kansas City, MO, USA, 20-24 May 2018; pp. 1-6.

24. Ganguly, B.; Konar, A. Kinect Sensor Based Gesture Recognition for Surveillance Application. arXiv 2018, arXiv:1812.09595.

25. Saeedi, S.; Moussa, A.; El-Sheimy, N. Context-aware personal navigation using embedded sensor fusion in smartphones. Sensors 2014, 14, 5742-5767. [CrossRef] [PubMed]

26. Atienza, R.O. Deep Learning for Smartphone-Based Human Activity Recognition Using Multi-sensor Fusion. In Lecture Notes of the Institute for Computer Sciences, Social Informatics and Telecommunications Engineering, Proceedings of the Wireless Internet: 11th EAI International Conference, WiCON 2018, Taipei, Taiwan, 15-16 October 2018; Springer: Cham, Switzerland, 2019 ; p. 65.

27. Guo, H.; Chen, L.; Chen, G.; Lv, M. Smartphones-based activity recognition independent of device orientation and placement. Int. J. Commun. Syst. 2016, 29, 2403-2415. [CrossRef] 
28. Wang, J.; Chen, Y.; Hao, S.; Peng, X.; Hu, L. Deep learning for sensor-based activity recognition: A survey. Pattern Recognit. Lett. 2019, 119, 3-11. [CrossRef]

29. Zhang, M.; Sawchuk, A.A. USC-HAD: A daily activity dataset for ubiquitous activity recognition using wearable sensors. In Proceedings of the 2012 ACM Conference on Ubiquitous Computing, Pittsburgh, PA, USA, 5-8 September 2012; pp. 1036-1043.

30. Attal, F.; Mohammed, S.; Dedabrishvili, M.; Chamroukhi, F.; Oukhellou, L.; Amirat, Y. Physical human activity recognition using wearable sensors. Sensors 2015, 15, 31314-31338. [CrossRef] [PubMed]

31. Bao, L.; Intille, S.S. Activity recognition from user-annotated acceleration data. In Lecture Notes in Computer Science, Proceedings of the International Conference on Pervasive Computing, Linz/Vienna, Austria, 21-23 April 2004; Springer: Berlin/Heidelberg, Germay, 2004; pp. 1-17.

32. Awais, M.; Chiari, L.; Ihlen, E.A.F.; Helbostad, J.L.; Palmerini, L. Physical Activity Classification for Elderly People in Free-Living Conditions. IEEE J. Biomed. Health Inform. 2019, 23, 197-207. [CrossRef]

33. Sztyler, T.; Stuckenschmidt, H.; Petrich, W. Position-aware activity recognition with wearable devices. Pervasive Mob. Comput. 2017, 38, 281-295. [CrossRef]

34. Atallah, L.; Lo, B.; King, R.; Yang, G.-Z. Sensor positioning for activity recognition using wearable accelerometers. IEEE Trans. Biomed. Circuits Syst. 2011, 5, 320-329. [CrossRef]

35. Malaise, A.; Maurice, P.; Colas, F.; Charpillet, F.; Ivaldi, S. Activity Recognition with Multiple Wearable Sensors for Industrial Applications. In Proceedings of the Advances in Computer-Human Interactions, Rome, Italy, 25-29 March 2018.

36. Uddin, M.Z. A wearable sensor-based activity prediction system to facilitate edge computing in smart healthcare system. J. Parallel Distrib. Comput. 2019, 123, 46-53. [CrossRef]

37. Chowdhury, A.; Tjondronegoro, D.; Chandran, V.; Trost, S.G. Physical Activity Recognition Using Posterior-Adapted Class-Based Fusion of Multiaccelerometer Data. IEEE J. Biomed. Health Inform. 2018, 22, 678-685. [CrossRef]

38. Mannini, A.; Sabatini, A.M.; Intille, S.S. Accelerometry-based recognition of the placement sites of a wearable sensor. Pervasive Mob. Comput. 2015, 21, 62-74. [CrossRef] [PubMed]

39. Qi, J.; Yang, P.; Hanneghan, M.; Tang, S.; Zhou, B. A Hybrid Hierarchical Framework for Gym Physical Activity Recognition and Measurement Using Wearable Sensors. IEEE Internet Things J. 2018, 6, 1384-1393. [CrossRef]

40. Ding, G.; Tian, J.; Wu, J.; Zhao, Q.; Xie, L. Energy efficient human activity recognition using wearable sensors. In Proceedings of the Wireless Communications and Networking Conference Workshops (WCNCW), Barcelona, Spain, 15-18 April 2018; pp. 379-383.

41. Martinelli, A.; Morosi, S.; Re, E.D. Daily movement recognition for dead reckoning applications. In Proceedings of the 2015 International Conference on Indoor Positioning and Indoor Navigation (IPIN), Banff, AB, Canada, 13-16 October 2015; pp. 1-8.

42. Liu, L.; Peng, Y.; Wang, S.; Liu, M.; Huang, Z. Complex activity recognition using time series pattern dictionary learned from ubiquitous sensors. Inf. Sci. 2016, 340, 41-57. [CrossRef]

43. Wu, H.; Wang, D.; Huang, Q.; Gao, L. Real-time continuous recognition of knee motion using multi-channel mechanomyography signals detected on clothes. J. Electromyogr. Kinesiol. 2018, 38, 94-102. [CrossRef] [PubMed]

44. Pannurat, N.; Thiemjarus, S.; Nantajeewarawat, E.; Anantavrasilp, I. Analysis of Optimal Sensor Positions for Activity Classification and Application on a Different Data Collection Scenario. Sensors 2017, 17, 774. [CrossRef]

45. Ehatisham-ul-Haq, M.; Azam, M.A.; Loo, J.; Shuang, K.; Islam, S.; Naeem, U.; Amin, Y. Authentication of smartphone users based on activity recognition and mobile sensing. Sensors 2017, 17, 2043. [CrossRef] [PubMed]

46. Zhu, J.; San-Segundo, R.; Pardo, J.M. Feature extraction for robust physical activity recognition. Hum. Centric Comput. Inf. Sci. 2017, 7, 16. [CrossRef]

47. Iqbal, A.; Ullah, F.; Anwar, H.; Ur Rehman, A.; Shah, K.; Baig, A.; Kwak, K.S. Wearable Internet-of-Things platform for human activity recognition and health care. Int. J. Distrib. Sens. Netw. 2020, 16, 1550147720911561. [CrossRef]

48. Siddiqui, U.A.; Ullah, F.; Iqbal, A.; Khan, A.; Ullah, R.; Paracha, S.; Shahzad, H.; Kwak, K.-S. Wearable-Sensors-Based Platform for Gesture Recognition of Autism Spectrum Disorder Children Using Machine Learning Algorithms. Sensors 2021, $21,3319$. [CrossRef]

49. Lee, K.; Kwan, M.-P. Physical activity classification in free-living conditions using smartphone accelerometer data and exploration of predicted results. Comput. Environ. Urban Syst. 2018, 67, 124-131. [CrossRef]

50. Yao, R.; Lin, G.; Shi, Q.; Ranasinghe, D.C. Efficient dense labelling of human activity sequences from wearables using fully convolutional networks. Pattern Recognit. 2018, 78, 252-266. [CrossRef]

51. San-Segundo, R.; Blunck, H.; Moreno-Pimentel, J.; Stisen, A.; Gil-Martín, M. Robust Human Activity Recognition using smartwatches and smartphones. Eng. Appl. Artif. Intell. 2018, 72, 190-202. [CrossRef]

52. Cherian, J.A. Recognition of Everyday Activities through Wearable Sensors and Machine Learning. Master's Thesis, Texas A \& M University, College Station, TX, USA, 2017.

53. Köping, L.; Shirahama, K.; Grzegorzek, M. A general framework for sensor-based human activity recognition. Comput. Biol. Med. 2018, 95, 248-260. [CrossRef]

54. Fiorini, L.; Bonaccorsi, M.; Betti, S.; Esposito, D.; Cavallo, F. Combining wearable physiological and inertial sensors with indoor user localization network to enhance activity recognition. J. Ambient. Intell. Smart Environ. 2018, 10, 345-357. [CrossRef]

55. Kwon, M.-C.; Choi, S. Recognition of Daily Human Activity Using an Artificial Neural Network and Smartwatch. Wirel. Commun. Mob. Comput. 2018, 2018, 2618045. [CrossRef] 
56. Zheng, X.; Wang, M.; Ordieres-Meré, J. Comparison of Data Preprocessing Approaches for Applying Deep Learning to Human Activity Recognition in the Context of Industry 4.0. Sensors 2018, 18, 2146. [CrossRef] [PubMed]

57. Cvetković, B.; Szeklicki, R.; Janko, V.; Lutomski, P.; Luštrek, M. Real-time activity monitoring with a wristband and a smartphone. Inf. Fusion 2018, 43, 77-93. [CrossRef]

58. Twomey, N.; Diethe, T.; Fafoutis, X.; Elsts, A.; McConville, R.; Flach, P.; Craddock, I. A comprehensive study of activity recognition using accelerometers. Informatics 2018, 5, 27. [CrossRef]

59. Gia, T.N.; Sarker, V.K.; Tcarenko, I.; Rahmani, A.M.; Westerlund, T.; Liljeberg, P.; Tenhunen, H. Energy efficient wearable sensor node for IoT-based fall detection systems. Microprocess. Microsyst. 2018, 56, 34-46.

60. BlueZ and Apt-Get Tool Library. Available online: http://jaymoss.co.uk/wp-content/plugins/litespeed-cache/tpl/banner/ john-logout-gcam/raspberry-pi-bluez-tutorial.html (accessed on 15 December 2019).

61. Hall, M.; Frank, E.; Holmes, G.; Pfahringer, B.; Reutemann, P.; Witten, I.H. The WEKA data mining software: An update. ACM SIGKDD Explor. Newsl. 2009, 11, 10-18. [CrossRef]

62. Guo, G.; Wang, H.; Bell, D.; Bi, Y.; Greer, K. KNN model-based approach in classification. In Lecture Notes in Computer Science, Proceedings of the OTM Confederated International Conferences, on the Move to Meaningful Internet Systems, Catania, Sicily, Italy, 3-7 November 2003; Springer: Berlin/Heidelberg, Germany, 2003; pp. 986-996.

63. Breiman, L. Random forests. Mach. Learn. 2001, 45, 5-32. [CrossRef]

64. Hamilton, H.J.; Cercone, N.; Shan, N. RIAC: A Rule Induction Algorithm Based on Approximate Classification; Computer Science Department, University of Regina: Regina, Canada, 1996.

65. Ye, J.; Chow, J.-H.; Chen, J.; Zheng, Z. Stochastic gradient boosted distributed decision trees. In Proceedings of the 18th ACM Conference on Information and Knowledge Management, Hong Kong, China, 2-6 November 2009; pp. 2061-2064. 